\title{
A necessidade metafísica do homem a partir da problematização do conceito de experiência em geral
}

\author{
Man's need for metaphysics from the question about the concept of \\ experience in general
}

\author{
Juliana dos Reis Cuenca \\ Mestranda em Filosofia pela Universidade Estadual de Londrina \\ E-mail: cuencajuliana@hotmail.com
}

\begin{abstract}
Resumo: 0 texto busca a problematização do conceito de totalidade do fenômeno ou experiência em geral, que são tomados como conceitos equivalentes. A partir do que Schopenhauer chama de "método da filosofia" baseado em Platão e Kant, ou seja, as leis de especificação e homogeneidade aplicadas às intuições e à própria experiência mesma, desenvolve-se o argumento de que a necessidade metafisica do homem também pode ser entendida como uma consequência da atividade da razão e não apenas por uma consciência trágica, dando ensejo ao que o filósofo considera como a atividade diferenciada do intelecto humano frente aos outros animais. 0 texto é desenvolvido predominantemente a partir da leitura dos livros I e II de $O$ mundo como vontade $e$ representação e de provocações extraídas das leituras de alguns comentadores.
\end{abstract}

Palavras-chave: Necessidade metafísica; Totalidade do fenômeno; Experiência em geral.

\begin{abstract}
The paper seeks to question the concept of phenomenon in its entirety or experience in general that are taken as equivalent concepts. From what Schopenhauer calls as philosophy's method based on Plato and Kant, or so, the laws of specification and homogeneity applied to the intuitions and experience itself; it is developed the argument that the man's need for metaphysics also can be understood as a consequence of rational activity and not only by a tragic consciousness, yielding what the philosopher considers as the differential activity of the human intellect compared to other animals. The essay develops predominantly by the readings of books I and II of The world as will and representation and teasing taken from readings of commentators of the author's work.
\end{abstract}

Keywords: Need for metaphysics; Phenomenon in its entirety; Experience in general. 
É consenso desde a antiguidade, entre os filósofos, que a curiosidade humana ou o que chamamos de espanto em relação ao mundo é responsável pela atividade diferenciada dos homens comparada à dos outros animais: o ser humano tem como necessidade intrínseca atribuir sentido ao mundo, seja por meio de mitos, religiões, filosofia ou ciência. Esse consenso se estabeleceu a partir do entendimento de que a razão constrói as mais diversas significações da existência humana no mundo (arte, cultura etc.), mas que não determina qual é o sentido do mundo mesmo, o seu conteúdo, entendendo que através da razão também se dão significações discrepantes com a realidade efetiva dos fenômenos. Isso significa que esse espanto se caracteriza como uma forma de se relacionar com o mundo e não de determinar o sentido ou significado das intuições que os homens possam ter dele.

O sentido do mundo é entendido primeiramente dentro de cada indivíduo como parte de um todo ao qual esse sentido não pode ser negado. A filosofia de Schopenhauer busca demonstrar como é possível a transição desse conhecimento que o homem tem do sentido (da totalidade) dos fenômenos em si mesmo para a atribuição desse sentido ao mundo todo, como se fosse também um conhecimento efetivo. Tal filosofia se vale do conhecimento da motivação da ação humana como engrenagem que leva à apreensão do sentido moral do mundo.

Schopenhauer estabelece a noção de necessidade metafísica do homem como sendo, em geral, essa busca pelo significado das intuições que temos do mundo, ou seja, um conhecimento para além do que se pode entender das relações entre objetos. Dessa maneira, o que se pretende ao longo do texto é compreender melhor esse conceito pela interpretação de que ele é característico do homem, assim como a razão, e deriva de sua atividade no contexto de que se equipara a uma problematização da existência (ou experiência em geral) feita pelo homem por meio da razão.

Desta forma, este trabalho parte da curiosidade despertada pela leitura de um trecho da obra de Eduardo Brandão, A concepção de matéria na obra de Schopenhauer, em que é defendido que apenas por meio da reassimilação do conceito de motivação entre as duas edições da dissertação Sobre a quádrupla raiz do princípio de razão suficiente é que se tornou possível, para Schopenhauer, o enfrentamento da tarefa acerca da significação (moral) do mundo. 
A questão tratada aqui também tem em vista mais dois trechos desenvolvidos na obra de Alexis Philonenko: o primeiro diz respeito à afirmação de que a filosofia schopenhaueriana se baseia em uma intuição que só pode ser "revelada" de maneira discursiva e, ainda assim, não em todos os seus pormenores, em si mesma. 0 segundo se refere ao modo como o homem se entende em sua individualidade como um homem e como consegue abandoná-la e perceber a universalidade das coisas à sua volta. Principalmente a partir desses dois pontos é que o trabalho se desenvolve, passando pelo modo como o homem entende a intuição e o modo como se desprende de sua unicidade.

Em outras palavras, enquanto Philonenko apresenta a ideia de que um homem "uno", indivíduo, que problematiza a experiência que tem, dando-se conta da existência universal das coisas como um todo, é possível relacionar essas linhas com o que foi descrito acima sobre a transposição do conhecimento acerca do sentido do mundo no próprio homem para o mundo todo. Assim também, como quando o comentador se refere à necessidade da "revelação discursiva" na filosofia de Schopenhauer, é possível comparar ao que escreve Eduardo Brandão sobre a reassimilação da motivação e da causalidade na obra do filósofo, ou seja, uma mudança discursiva que se relaciona com a problematicidade da existência proposta através da razão.

Apesar de partir do texto de dois comentadores da obra de Schopenhauer, o artigo não pretende defender a crítica feita por nenhum deles. No entanto, de modo geral, o uso desses textos será necessário como pontos de vista divergentes ou não e que contribuem para o conhecimento do tema proposto. Isso significa que os comentadores primariamente servem como uma espécie de "gatilhos" para a interpretação proposta aqui. Em referência a Schopenhauer, como ponto de interesse máximo do que aqui desenvolvemos, tem-se a problematização da totalidade do fenômeno como característica da disposição metafísica do homem. E todos esses pontos são importantes como base em vista do que se pretende alcançar com esse trabalho.

0 ponto central é demonstrar a necessidade metafísica como algo relacionado apenas ao homem com base em uma interpretação própria de que esse conceito não se dá por meio de um "insight", mas que existe um caminho discursivo 
que leva ao fato de que o homem precisa atribuir sentido às suas intuições, ou seja, é uma tentativa de resposta para a questão proposta por Philonenko sobre como o homem deixa o entendimento de sua unicidade e se agarra à possibilidade da universalidade das coisas no mundo; é uma tentativa de colocar a experiência em geral na forma do discurso. Portanto, experiência em geral e totalidade do fenômeno são entendidos como conceitos equivalentes no sentido que carregam consigo a perspectiva de uma metafísica que se pretende imanente, ou seja, se apresenta no campo dos fenômenos, e ainda porque representam a "universalização" do que o conhecimento de cada objeto ou fenômeno único pode oferecer: problematizar a existência.

E, ainda, essa discussão permite abranger um tema maior da obra do filósofo, que é a transposição do sentido moral das ações do homem para todas as intuições através do argumento da analogia, algo que pode ser levado a cabo pela equivalência entre a vontade individual do homem e a vontade que se objetiva no mundo. Esse último tópico não será desenvolvido ao longo do texto. No entanto, o trabalho percorre o mesmo caminho de intersecção mediante a leitura dos livros I e II de $O$ mundo como vontade e representação, completando a relação entre os dois primeiros livros da obra máxima do autor e abrangendo as duas perspectivas do mundo, como proposto por Schopenhauer.

\section{Sobre a necessidade metafísica baseada no conceito de experiência em geral}

Com a intenção de pensar um dos principais temas da filosofia de Schopenhauer, a metafísica imanente, esse trabalho se desenvolve a partir do problema da necessidade inerente do reconhecimento moral do homem mediante a vontade para atribuir às intuições do mundo uma consequente significação, no sentido de algo que as "justifique" para além do fenômeno.

No primeiro momento, sobre a necessidade metafísica do homem, faz-se a tentativa de percorrer um caminho que a justifique racionalmente em vista do conceito de experiência em geral (já que diz respeito apenas aos seres humanos). É através das leis de especificação e homogeneidade, defendidas por Schopenhauer com base em Platão e Kant - como princípios transcendentais da razão e método 
da filosofia ${ }^{1}$ que a necessidade metafísica se justificará, levando até à ideia sobre a significação da própria existência e desenvolvendo os conceitos de experiência interna e externa.

Uma das principais características da filosofia de Schopenhauer consiste no fato de o filósofo buscar a construção de um pensamento único. Isso significa que, além de se dedicar a tópicos específicos do pensamento, como a ética ou a metafísica, ele ainda desenvolve conceitos que abarcam metodologicamente toda a sua filosofia e propiciam o que se espera desse pensamento: que seus temas de estudo tenham conexão entre si de maneira orgânica no sentido de que cada parte pressupõe reciprocamente a outra, ao contrário da concepção corrente de um sistema em que todas as áreas e temas do pensamento se desenvolvem sobre uma base comum, sem que ela mesma seja atingida nesse processo de desenvolvimento.

É essa conexão entre temas e a interdependência dos conceitos na filosofia de Schopenhauer que leva quem quer estudá-la a um trânsito entre textos para que se entendam melhor suas especificidades, e isso significa que não apenas $O$ mundo como vontade e representação, mas também seus textos complementares do Tomo II da obra e livros que tratam de temas diferentes ao desse trabalho, são necessários para o problema, corroborando com a ideia do filósofo sobre um pensamento único e também com aquilo que diz respeito ao texto aqui desenvolvido: a necessidade de se permear o campo das características do conhecimento e a atividade da razão para que se entenda, pela aplicação das leis de especificação e homogeneidade, o conceito de experiência em geral e, assim, explanar a necessidade metafísica do homem.

Especificamente sobre a questão de um sentido moral do mundo, o autor defende ser um consenso entre os povos o fato que o mundo possua uma significação moral além da física ${ }^{2}$ e ainda que aquilo de essencial na existência se encontra na moralidade do agir humano. Isso significa, de maneira geral, que aquilo que o autor chama de significação/sentido moral do mundo diz respeito à essência da existência além do seu sentido físico ou fenomênico. Ele também dará como base ao sentido do mundo a mesma base da moralidade do agir humano: a vontade. Ainda sobre o trânsito entre textos e tendo em vista a necessidade de um 
fio condutor que pressuponha cada ponto da filosofia do autor, quando se entende que ela propõe um pensamento único, é importante considerar que, para Schopenhauer, a filosofia enquanto atividade que lida com conceitos se desenvolve no campo do conhecimento abstrato ${ }^{3}$ e pressupõe a razão e sua atividade.

Do mesmo modo, a atividade da razão também é necessária para a coesão dos sistemas de conhecimento das ciências, de forma que a filosofia e as ciências, de algum modo, se encontram no mesmo patamar do conhecimento abstrato. Nesse sentido, já no texto Sobre a quádrupla raiz do princípio de razão suficiente, Schopenhauer defende o método da filosofia em referência à suas duas grandes influências, Platão e Kant, como sendo baseado em duas leis: a lei de especificação e a de homogeneidade (reiterando o caráter de princípio transcendental da razão atribuído a essas duas leis ${ }^{4}$ ). Dessa forma, se pressupõe aqui que o autor segue com o método proposto buscando satisfazer as duas leis não apenas na filosofia, mas em todo o campo do conhecimento abstrato, traçando o fio condutor necessário a princípio.

A lei de especificação orienta que não se deve esquecer a diferença entre vários conhecimentos reunidos sob o nome de um mesmo conceito, ou ainda, a importância de não desconsiderar a individualidade de cada objeto da representação:

É da maior importância isolar os conhecimentos que, pela sua espécie e origem, são distintos de outros conhecimentos e impedilos cuidadosamente de se misturar e confundir com outros, com os quais se encontram ordinariamente ligados no uso. [...] diz respeito ainda mais ao filósofo, a fim de poder determinar a parte que um modo particular do conhecimento tem no uso corrente do entendimento, seu valor próprio e influência 5 .

Em sua obra sobre o princípio de razão suficiente, o autor se dedica à aplicação da lei de especificação a tal princípio, já que, de acordo com ele, a especificação produz progressos no que respeita às faculdades cognoscitivas; ao

\footnotetext{
${ }^{3}$ No ensaio Sobre a quádrupla raiz do princípio de razão suficiente, enquanto desenvolve sua teoria das faculdades cognitivas, Schopenhauer as divide em dois tipos: as responsáveis pela intuição (princípios de razão de ser: tempo e espaço; princípio de razão do devir: causalidade; e princípio de razão do agir: motivação) e as responsáveis pelo conhecimento abstrato (princípio de razão de conhecer: razão).

${ }^{4}$ Cf. SCHOPENHAUER, A. PR, § 1, p. 29.

${ }^{5}$ KANT, I. Crítica da razão pura, p. 663.
} 
contrário da lei de homogeneidade, que produz muitos erros apesar de ser aplicada a essas faculdades com mais frequência para explicá-las ${ }^{6}$.

Considerando que a forma da representação, transcrita na relação intransponível entre sujeito e objeto, se dá por meio da atribuição das formas do princípio de razão suficiente (encontradas a priori no sujeito) ao objeto; e que as "leis transcendentais" da razão (especificação e homogeneidade) se aplicam ao princípio de razão quando esta desenvolve sua atividade de conhecimento abstrato tanto como filosofia quanto como ciência, é possível dizer que, para Schopenhauer, essa lei se aplicaria à própria experiência, já que todo conhecimento está em algum momento ligado à intuição. Isso quer dizer que, no caso da especialização (por exemplo), a cognição humana é capaz de compreender desde diferentes áreas de conhecimento até a existência da particularidade/individualidade entre objetos do conhecimento.

Já a lei de homogeneidade orienta a uma ação contrária à primeira: pela observação da semelhança entre vários objetos do conhecimento considerados individualmente, se estabelece relações e se agrupam as variedades sob um mesmo conceito:

Tal como o entendimento reúne por conceitos o que há de diverso no objeto, assim também a razão, por sua vez, reúne por intermédio das ideias o diverso dos conceitos, propondo uma certa unidade coletiva, como fim aos atos do entendimento, o qual, de outra forma, apenas teria de se ocupar da unidade distributiva ${ }^{7}$.

Dessa forma, ainda se deve levar em conta que as duas leis que orientam o método da filosofia são, para Schopenhauer, sob influência de Kant, princípios transcendentais da razão, o que torna possível concluir que tais leis não podem ser deixadas de lado no desempenho da sua atividade tanto na filosofia quanto nas ciências. Assim, da mesma forma que se pensou a aplicação da lei de especificação tanto às formas do princípio de razão como à própria experiência, também é possível pensar a aplicação da lei de homogeneidade a esses mesmos elementos.

\footnotetext{
${ }^{6}$ Cf. SCHOPENHAUER, A. PR, § 2.

${ }^{7}$ KANT, I. Crítica da razão pura, p. 534. - Nessa citação não se considera a diferença que há entre o que significa entendimento e razão para Kant e Schopenhauer. Deve-se levá-la em conta apenas como exemplo da ideia geral a qual Schopenhauer se refere ao tratar da lei de homogeneidade.
} 
O empenho do filósofo para satisfazer as duas leis é identificado já no texto sobre a quádrupla raiz por sua aplicação da lei de especificação ao princípio de razão, conforme foi dito. 0 efeito desse processo é o estabelecimento das bases das várias ciências possíveis quando se tem em mente que uma experiência só é entendida como tal e só pode se tornar objeto de uma ciência quando está submetida ao princípio de razão que estabelece a conexão entre os conhecimentos em um sistema.

Portanto, também o conhecimento do homem, de maneira geral, sempre estará submetido ao princípio de razão, pois independentemente de suas formas, sempre deriva da fonte da experiência: o princípio de razão e a relação entre sujeito e objeto. Nesse sentido, ficam claros os resultados que derivam da lei de especificação para a filosofia de Schopenhauer; no entanto, a lei de homogeneidade ainda resulta problemática como o próprio autor declara quando se refere à sua aplicação ao princípio de razão; o que resta acrescentar ainda é a sua aplicação sobre a própria experiência como proposto anteriormente para a lei de especificação.

Entende-se, assim, a lei de especificação aplicada ao princípio de razão (tornando-o quádruplo), que se aplica como consequência também à própria experiência humana, já que uma atividade da razão está trabalhando sobre as formas do conhecimento (e a relação entre sujeito e objeto é essencial aqui, como dito anteriormente sobre a necessária relação desses elementos para a representação). Desse modo, é através do exercício da lei de homogeneidade, que concentra as semelhanças das intuições do entendimento e as reproduz como conceitos, que o conhecimento racional é possível. 0 que se pretende dizer com isso está baseado no trecho referente à criação de conceitos:

Também é possível defini-las como representações de representações. Pois para formá-las a faculdade de abstração decompõe as representações completas, isto é, intuitivas [...], em suas partes constitutivas para isolá-las e poder conhecê-las cada uma por si como qualidades ou relações diferentes das coisas ${ }^{8}$.

Ou seja, a atividade da razão desenvolvida por meio da abstração se torna possível com ajuda da lei de homogeneidade.

${ }^{8}$ SCHOPENHAUER, A. PR, § 26, p. 149. 
Em resumo, caberia à lei de especificação subsumir todas as experiências possíveis ao homem em áreas diferentes, pelas quais as ciências serão responsáveis; e à lei de homogeneidade cabe agrupá-las, mediante a atividade da abstração, em conceitos que serão responsáveis pela elaboração de um conhecimento racional. Portanto, o conhecimento racional (enquanto abstração) é levado a cabo quando as duas leis são satisfeitas para que não haja tamanha especificação na qual cada objeto individual seja levado em consideração como uma "categoria" diferente de conhecimento, nem uma homogeneidade tamanha que trata de conceitos aos quais não se reconhece o conteúdo.

Quanto aos problemas sobre a aplicação da lei de homogeneidade já citados por Schopenhauer, é possível entender, em primeiro lugar, que quanto às formas do princípio de razão, a lei de homogeneidade levaria apenas a uma compreensão da ciência ou conhecimento em geral em suas características básicas, ou seja, a relação entre sujeito e objeto e a necessidade de um princípio para regê-la. Isso significa que as várias áreas delimitadas através de cada forma do princípio de razão (por exemplo, a aritmética ou a geometria) perderiam sua característica própria se não na cognição humana, pelo menos no estudo sobre essas áreas (já que elas não deixariam de existir por isso) o que, de acordo com o filósofo, causa atrasos e retrocessos ${ }^{9}$.

Ainda é possível levar em conta a homogeneidade, como proposta acima, "transfigurada" naquilo que não se aplicaria apenas à intuição (já baseada nas formas do princípio de razão), mas na própria experiência, quer dizer, levando o exercício da razão para além do proposto pelo autor e na compreensão de que a cognição do homem permite que ele entenda que sob um único conceito existam várias representações individuais; assim, é razoável a proposta de um afastamento ainda maior das intuições, ou seja, pensar não apenas o conteúdo dos conceitos enquanto intuições de objetos, mas além, no que todos eles têm em comum, enquanto realidade efetiva.

Pode parecer confuso, a princípio. No entanto, se pode dizer que a experiência em si mesma se tornou um conceito abstraído pelo raciocínio acima, através das seguintes etapas: primeiro, a atividade da razão abstrai o diferente e

\footnotetext{
${ }^{9}$ É preciso lembrar que é justamente por conta desses problemas que Schopenhauer apresenta
} como parte da sua filosofia a aplicação da lei de especificação ao princípio de razão. 
une o comum das intuições (a realidade efetiva) em conceitos; segundo, se abstrai o diferente e une o comum da própria realidade efetiva e se problematiza a existência por ela mesma através da experiência.

Isso significaria, de maneira geral, o reconhecimento daquilo que cada experiência específica tem em comum e a consideração de uma experiência do total, ou uma experiência em geral, já que não restariam as especificidades das ciências que individualizam as experiências.

O mais perfeito e satisfatório conhecimento é o intuitivo, mas ele é limitado somente ao particular, ao individual. A combinação do múltiplo e do variado através de uma representação só é possível através do conceito, em outras palavras, pela omissão da diferença. Consequentemente, o conceito é uma forma muito imperfeita de representar coisas $^{10}$.

Nesse sentido, tendo em mente o que foi dito anteriormente sobre o conhecimento e a experiência, ou seja, que só são possíveis sob alguma das formas do princípio de razão (e, com isso, aponta uma das imperfeições do intelecto humano), nesse cenário da consideração de uma experiência em geral e da imperfeição do conhecimento baseado em conceitos por sua significação em referência à intuição, a saída de tal impasse seria a investigação acerca da significação das próprias intuições ${ }^{11}$. Isso leva à necessidade da busca de um fundamento das intuições para além da própria experiência, do qual receberiam seu significado ou sentido (já que, no limite, a experiência é necessária à intuição como sua forma, não como conteúdo).

Dizendo de maneira mais detalhada, o problema a ser enfrentado aparece da seguinte forma: todo nosso conhecimento se baseia em uma razão suficiente para que exista, a qual é sempre buscada na experiência. Um conceito tem sua razão de existência na abstração que foi feita das intuições e, no limite, tem sua significação e conteúdo pautados a partir delas. Dessa forma, quando se chega ao próprio limiar da experiência em geral, ela não tem um fundamento que a justifique como as intuições têm, a não ser a existência mesma, como fundamento além da experiência ${ }^{12}$.

${ }^{10}$ SCHOPENHAUER, A. MVR II, cap. XV, p. 224 e 225.

${ }^{11}$ Cf. SCHOPENHAUER, A. MVR I, § 17, p. 151.

12 Ainda é possível apresentar aqui a pressuposição da asseidade da vontade citada por 
[...] a disposição metafísica propriamente dita também nos torna capazes de espanto frente as coisas comuns de nossa vida cotidiana, o que induz a tratar do problema que consiste em dizer o que são em geral os fenômenos. [...] Quanto menos expressiva for uma pessoa do ponto de vista intelectual, menos enigmática a existência lhe parecerá13.

A esse "além da experiência" Schopenhauer chama de metafísica, e a essa busca pelo fundamento além da experiência que daria significação às intuições o autor dá o nome de necessidade metafísica do homem; o que significa que, mesmo com a impossibilidade de um conhecimento que se poderia chamar de científico para além da experiência, o homem ainda carrega em si o "senso" de uma experiência em geral (o que significa que essa necessidade metafísica não carrega o caráter de intencionalidade), que advém do fato de a lei de homogeneidade ser uma atividade da razão e, nesse sentido, poder-se-ia afirmar que a necessidade metafísica seria consequência dessa atividade. Schopenhauer trata esse tema ao longo de sua obra, desenvolvendo a sua metafísica imanente.

0 que decorre disso é que se tem uma ciência que explica a relação das coisas NO mundo e como elas não poderiam deixar de ser já que, para Schopenhauer, o conhecimento se baseia na relação entre sujeito (com as formas subjetivas do conhecimento - o princípio de razão ${ }^{14}$ ) e objeto (através da matéria) que leva apenas até a fonte do problema da experiência em geral, não sendo suficiente como resposta ao problema da significação das intuições, pois diz respeito ao fenômeno, ou seja, ao ser individual das coisas e não a algo que a fundamente.

[...] A inadequação do naturalismo puro, como eu disse, aparece pela primeira vez, no próprio caminho empírico, pois toda explicação física parte do particular para a sua causa, mas a cadeia de tais causas [...] corre de volta para o infinito, onde absolutamente nenhuma causa poderia ser a primeira. Mas, então,

\footnotetext{
Schopenhauer em relação ao tema da liberdade e imputabilidade, mas que também serve para entender um fundamento para além da experiência. - Cf. SCHOPENHAUER, A. N, p. 210.

${ }^{13}$ SCHOPENHAUER, A. MVR II, cap. XVII, p. 250.

${ }^{14}$ Enquanto as formas do princípio de razão são encontradas a priori no sujeito cognoscente, elas não se aplicam a ele. Disso surge a crítica ao dogmatismo feita por Schopenhauer, em que a pretensão de conhecimento partindo apenas do sujeito ou apenas do objeto a partir da aplicação errônea da causalidade (princípio de razão do devir) ao sujeito já é considerada absurda.
} 
a eficácia de cada causa é referida a uma lei da natureza, e essa lei ao final a uma força da natureza que permanece como qualquer coisa absolutamente inexplicável. Este inexplicável, no entanto, ao qual todos os fenômenos dados [...] se referem, em tão naturalmente explicável mundo, apenas revelam que toda a natureza de tal explicação é apenas condicional ${ }^{15}$.

A insuficiência da chamada "resposta naturalista", ou seja, baseada apenas na ciência, aponta para a necessidade de uma explicação da totalidade do fenômeno para que o ser individual possa ser compreendido em sua plenitude; e é a filosofia a responsável por interpretar a sua forma (dada pelo conhecimento, na experiência externa) e conteúdo, aquilo pelo qual a experiência é entendida enquanto tal: o que condiciona a experiência ou torna a natureza possível, aquilo ao qual a metafísica quer oferecer uma chave e que transforma a própria existência em problema, a significação das intuições.

Aqui, no entanto, são necessários dois adendos: em primeiro lugar, é preciso entender que conhecemos os objetos na sua relação com outros e nos vários tipos de relações possíveis. Assim, quando se problematiza esse senso da experiência em geral e a busca pela significação das intuições, não é mais sobre as relações entre os objetos que se diz respeito, mas sobre o significado e fundamento de cada representação individualmente considerada. Em segundo lugar, é importante reforçar o caminho traçado nesse trabalho, quer dizer, se a insuficiência da resposta naturalista desenvolve o traçado da resposta para a busca do significado das intuições, por que é necessária a justificação pelas leis de homogeneidade e especificação? Ora, o que se busca é justificar o senso de que as intuições têm significado baseado no "incontentamento" acerca da simples representação do mundo.

Porém, o que agora nos impele à investigação é justamente não mais estarmos satisfeitos em saber que possuímos tais e tais representações, conectadas conforme estas e aquelas leis, cuja expressão geral é sempre o princípio de razão. Queremos conhecer a significação dessas representações ${ }^{16}$.

Portanto, a totalidade do fenômeno ou o que se pode chamar de "a própria existência” (através não só da forma dada pela experiência, mas do seu conteúdo) 
se estabelece como problema efetivamente humano e parte daquilo que caracteriza a diferença entre homens e os outros animais, ou seja, a disposição metafísica, seguida daquilo que a torna possível: o distanciamento da função do intelecto em relação à vontade, ou seja, o intelecto humano, como característica de um maior desenvolvimento do cérebro em relação aos outros animais, não está mais em função apenas do reconhecimento de motivações para uma vontade individual e a consequente ação, também pode planejar e almejar coisas em relação ao seu futuro que leva ao conhecimento da morte e do sofrimento e condicionam a interpretação metafísica e ao assombro filosófico em relação à existência.

De acordo com Gardiner, "a filosofia 'transcendental', no sentido kantiano, é a filosofia que reconhece que a estrutura fundamental do nosso conhecimento é determinada por categorias e princípios que têm sua origem em nós mesmos"17. Gardiner desenvolve ainda a problematização schopenhaueriana a respeito da metafísica transcendental de Kant, baseando-se no conceito de coisa em si: ora, se a metafísica transcendental estabelece limites para o conhecimento humano circunscrito na experiência, como o conceito de coisa em si (que está além da experiência) se relacionaria com os fenômenos?

É em relação a isso que o caminho "alternativo" de Schopenhauer (que se dá sob o nome de metafísica imanente) começa a tomar formas próprias. Gardiner acrescenta, em referência a Schopenhauer:

Se admite que Kant foi capaz de mostrar por que seus predecessores haviam fracassado sempre, ao expor o vazio de toda pretensão de conhecimento que transcenda os limites da experiência possível. Mas, por que, mais uma vez, há de se supor que todas as metafísicas têm de ter a característica serem "transcendentes"18?

Ainda em referência a Kant, mas tomando um desvio importante no caminho, a metafísica schopenhaueriana enquanto "ciência da experiência em geral" advém da própria experiência onde o problema se dá e, pelo fato de ainda dizer respeito apenas aos fenômenos, quer dizer, ao elemento subjetivo deles (que só se expressa através deles e ao qual se pode almejar algum conhecimento), não

${ }^{17}$ GARDINER, P. Schopenhauer, p. 70.

18 GARDINER, P. Schopenhauer, p. 91. 
diz respeito à coisa em si, digamos, de maneira pura. 0 que se pretende dizer com isso é que a coisa em si se dá em sua essência por meio da matéria, em referência ao fenômeno, sendo o único caminho pelo qual se poderia alcançá-la. Nesse sentido, tendo a coisa em si baseada na matéria, o autor configura sua metafísica como imanente e ainda deve levar em consideração as fontes cognoscitivas que a tornam possível.

Em vista disso e apontando para a solução do problema entre um conhecimento para além da experiência externa, para aquilo que a fundamenta, e a necessidade das formas cognoscitivas que levam à metafísica imanente, Schopenhauer desenvolve (reformulando alguns de seus textos ao longo do tempo para que se adequem à teoria, como será apresentado posteriormente) um conceito fundamental para o entendimento de ideias recorrentes em sua obra (como, por exemplo, a vontade e a consciência): o conceito da experiência interna.

A diferenciação entre os conceitos de experiência externa e interna como aquilo que permitiria a pretensa metafísica schopenhaueriana pode estar baseada, de acordo com Eduardo Brandão ${ }^{19}$, nas alterações feitas pelo autor nas edições posteriores de alguns textos que levariam ao entendimento de que o conhecimento poderia ser transfigurado a partir de suas bases no polo entre sujeito e objeto (entendido em sentido individualizado), para sujeito e matéria: "Schopenhauer indica haver uma amplitude a ser considerada na noção de matéria [...] (e, não por acaso, Schopenhauer estabelece três formas de causalidade - a matéria é causalidade)"20.

De acordo com Brandão, essa diferenciação ocorre da seguinte maneira: a matéria (Stoff), enquanto objeto, se dá na sua relação objetiva com o entendimento, simplesmente performada pelo princípio de razão suficiente. Já a matéria (Materie) é entendida pela abstração das formas do princípio de razão que o sujeito poderia atribuir a ela. Dessa forma, mais uma vez pode-se defender que essas alterações dão ensejo àquela homogeneização problematizada anteriormente, necessária como método à filosofia de Schopenhauer. Já que é possível entender a "individualização" tratada na relação entre sujeito e objeto (Stoff) como elemento da especificação necessária à ciência, nesse sentido, a relação entre sujeito e

19 BRANDÃO, E. A concepção de matéria na obra de Schopenhauer, p. 45.

20 Ibidem. 
matéria (Materie) estaria isenta, pelo menos em parte, dessa individualização, como é necessária ao senso daquela experiência em geral já referida.

Como último adendo, ainda é necessário esclarecer que, entendendo a metafísica como imanente, não se pode atribuir a ela uma certeza, nem muito menos pretender que resolva todos os problemas que subsistiriam à relação entre experiência externa e interna, tema cujo desenvolvimento não vem ao caso aqui.

Tendo em vista os pontos apresentados anteriormente sobre o conhecimento em Schopenhauer, e levando em conta a diferenciação das experiências externa e interna, também é necessária a apreciação da função do intelecto em cada caso. Enquanto à experiência externa são necessárias as formas do conhecimento que levam até ela, a individualização sob o tempo e o espaço, uma visão objetiva do intelecto diria respeito apenas às relações que o sujeito enquanto cognoscente, ou seja, aquele que detém as formas do conhecimento, estabelece com as coisas no mundo. Isso quer dizer que nessa visão o intelecto realizaria a atividade para a qual foi determinado: o simples reconhecimento dos motivos para uma vontade individual que se exteriorizará. No entanto, seria o seu duplo, ou seja, uma visão subjetiva do intelecto, que impele até a experiência interna e que, com ela, leva à negação da consideração das intuições do mundo como desprovidas de significação e providas apenas de uma necessidade inexorável. A visão subjetiva do intelecto diz respeito apenas a um "objeto encontrado" temporalmente, o reconhecimento daquilo que nos significaria enquanto objetos no mundo: a vontade.

Por fim, podemos afirmar que a demonstração de que a necessidade metafísica do homem pode ser "reconstruída" mediante o discurso entendido enquanto produto da razão foi satisfeita a partir da ideia de que tal necessidade compõe o desenvolvimento do intelecto humano naquilo que o constitui em suas diferenças com os outros animais, e não apenas devido a uma intuição que o homem tenha ou o sentimento de que essa intuição tenha importância no significado que ele atribui ao mundo.

\section{Considerações finais}


0 tema acerca da necessidade de atribuir um sentido às coisas do mundo para além de uma intelecção física da realidade efetiva dessas coisas é caro à filosofia, assim como ao próprio ser humano. Pensar uma interpretação metafísica do mundo como necessária ao homem não é um problema novo a ser considerado. Assim também, a questão que perpassa esse problema não pode ser deixada de lado quando se pretende estudá-lo: por que é necessária ao homem uma interpretação metafísica? Essa interpretação poderia, de alguma forma, ser comparada às formas de cognição humana? Essa necessidade poderia ser atribuída também à razão?

Schopenhauer desenvolve a questão da necessidade metafísica do homem baseado principalmente na ideia de "consciência trágica" do homem, ou seja, a consciência sobre sua própria existência, seu futuro e morte. No entanto, como esse texto não teve pretensão de desenvolver o problema baseado nesse aspecto do pensamento do autor, este não foi o ponto central aqui tratado. Ao contrário, tentou-se uma análise diferenciada.

Dessa forma, é necessário considerar que, em busca de uma "visão alternativa", foi dado menos ênfase à "consciência trágica" do homem do que às leis de especificação e homogeneidade como atividade da razão, ou seja, a necessidade metafísica do homem foi tratada menos como um fato que surge pela consciência e que irá morrer do que como uma consciência da experiência em geral. Diga-se, no entanto, que a presente hipótese de modo algum partiu do pressuposto de uma tentativa de "racionalização" da filosofia de Schopenhauer, mas de um recorte conceitual específico que o próprio filósofo permite nas entrelinhas de alguns dos seus textos.

\section{Referências bibliográficas}

BRANDÃo, E. A concepção de matéria na obra de Schopenhauer. São Paulo: Humanitas, 2008.

GARDINER, P. Schopenhauer. Tradução: Ángela Saiz Sáez. México: Breviarios del fondo de cultura económica, 1997.

KANT, I. Crítica da razão pura. Trad. Manuela Pinto dos Santos e Alexandre Fradique Morujão. Lisboa: Fundação Calouste Gulbenkian, 2010. 
PHILONENKO, A. Schopenhauer: uma filosofia de la tragédia. Trad. Gemma Muñoz-Alonso. Barcelona: Editorial Anthropos, 1989.

SCHOPENHAUER, A. De la cuadruple raiz del principio de razon suficiente. Trad. Leopoldo Eulogio Palacios. Madrid: Editorial Gredos, 1998.

SCHOPENHAUER, A. O mundo como vontade e como representação. Tomo I. Trad. Jair Barboza. São Paulo: Editora UNESP, 2005.

SCHOPENHAUER, A. O mundo como vontade e representação. Tomo II, vol. 1. Trad. Eduardo Ribeiro da Fonseca. Curitiba: Editora UFPR, 2014.

SCHOPENHAUER, A. Sobre a vontade na natureza. Trad. Gabriel Valladão Silva. Porto Alegre: L\&PM, 2013.

Recebido: $16 / 11 / 15$

Received: 11/16/15

Aprovado: $17 / 02 / 16$

Approved: 02/17/16 